\title{
Infusion of Brain-Derived Neurotrophic Factor into the Lateral Ventricle of the Adult Rat Leads to New Neurons in the Parenchyma of the Striatum, Septum, Thalamus, and Hypothalamus
}

\author{
Viorica Pencea, ${ }^{1}$ Kimberly D. Bingaman, ${ }^{1,2}$ Stanley J. Wiegand, ${ }^{3}$ and Marla B. Luskin ${ }^{1}$ \\ Departments of ${ }^{1}$ Cell Biology and ${ }^{2}$ Neurosurgery, Emory University School of Medicine, Atlanta, Georgia 30322, and \\ ${ }^{3}$ Regeneron Pharmaceuticals Inc., Tarrytown, New York 10591
}

The findings that brain-derived neurotrophic factor (BDNF) promotes in vitro the survival and/or differentiation of postnatal subventricular zone (SVZ) progenitor cells and increases in vivo the number of the newly generated neurons in the adult rostral migratory stream and olfactory bulb prompted us to investigate whether the infusion of BDNF influences the proliferation and/or differentiation of cells in other regions of the adult forebrain. We examined the distribution and phenotype of newly generated cells in the adult rat forebrain $16 \mathrm{~d}$ after intraventricular administration of BDNF in conjunction with the cell proliferation marker bromodeoxyuridine (BrdU) for $12 \mathrm{~d}$. BDNF infusion resulted in numerous BrdU ${ }^{+}$cells, not only in the SVZ lining the infused lateral ventricle, but moreover, in specific parenchymal structures lining the lateral and third ventricles, including the striatum and septum, as well as the thalamus and hypothalamus, in which neurogenesis had never been demonstrated previously during adulthood. In each region, newly generated cells expressed the neuronal marker microtubule-associated protein-2, or neuron-specific tubulin, identified by the antibody TuJ1. The percentage of the newly generated cells expressing TuJ1 ranged from 27 to $42 \%$, suggesting that the adult forebrain has a more profound capacity to produce neurons than recognized previously. The extent of cell proliferation after BDNF infusion was correlated with the level of expression of full-length TrkB, the high-affinity receptor for BDNF, despite the fact that the $\mathrm{BrdU}^{+}$cells were not themselves TrkB ${ }^{+}$. Collectively, our results demonstrate that the adult brain parenchyma may recruit and/or generate new neurons, which could replace those lost as a result of injury or disease.

Key words: brain-derived neurotrophic factor; cell proliferation; forebrain parenchyma; intraventricular infusion; postnatal neurogenesis; subventricular zone
The majority of the cells in the mammalian forebrain arise prenatally (Sidman and Rakic, 1973; Raedler and Raedler, 1978). However, it is now established that, in addition to the production of sensory neurons and supporting cells in the olfactory epithelium (Graziadei and Monti Graziadei, 1976; Huard et al., 1998), both neurons and glia continue to be generated in restricted adult mammalian forebrain structures, including the hippocampus (Altman and Das, 1965; Schlessinger et al., 1975; Kaplan and Bell, 1984; Kuhn et al., 1996; Palmer et al., 1997) and the subventricular zone (SVZ) lining the lateral ventricles (Privat, 1975; Vaysse and Goldman, 1990; Levison and Goldman, 1993; Luskin, 1993; Lois and Alvarez-Buylla, 1994). Recent studies have raised the possibility that the parenchyma of the adult forebrain also harbors progenitor cells for neurons (Reynolds et al., 1992; Palmer et al., 1995; Marmur et al., 1998; Magavi et al., 2000). The source and proliferative potential of these progenitors have not been fully determined.

In vitro studies have revealed that the adult striatal SVZ can be induced to generate both neurons and glia under the influence of growth factors (Reynolds et al., 1992; Reynolds and

\footnotetext{
Received Feb. 20, 2001; revised June 5, 2001; accepted June 7, 2001.

This work was supported by National Institute of Deafness and Other Communicative Disorders Grant RO1 DC03190 (M.B.L.) and by Regeneron Pharmaceuticals, Inc. We are grateful to Dr. Giri Venkatraman, Dr. Volkan Coskun, and Joanna Bonsall for their critical and helpful comments on this manuscript and to Dr. Stuart C. Feinstein for his generous gift of anti-TrkB.

Correspondence should be addressed to Dr. Marla B. Luskin, Department of Cell Biology, Emory University School of Medicine, 1648 Pierce Drive, Atlanta, GA 30322. E-mail: luskin@cellbio.emory.edu.

Copyright (ㄷ) 2001 Society for Neuroscience $0270-6474 / 01 / 210001-12 \$ 15.00 / 0$
}

Weiss, 1992, 1996; Gritti et al., 1999). Furthermore, the in vivo exposure of the adult forebrain SVZ to neurotrophins yields an increase in the number of progenitor cells, as well as the production of newly generated neurons (Craig et al., 1996; Kuhn et al., 1997; Zigova et al., 1998). Administration of either epidermal growth factor (EGF) or tumor growth factor- $\alpha$ (TGF- $\alpha$ ) into mouse(Craig et al., 1996) or of either EGF or fibroblast growth factor-2 (FGF-2) into rat (Kuhn et al., 1997) resulted in an expansion of the SVZ surrounding the infused lateral ventricle, as well as newborn cells in the nearby striatum and septum. However, although both EGF and FGF-2 amplified the number of striatal SVZ progenitors in the adult brain, neither treatment resulted in a significant increase in the production of neurons in the forebrain parenchyma.

In this study, we analyzed the rat forebrain SVZ and parenchyma for the presence of newly generated cells after intracerebroventricular infusion of brain-dervied neurotrophic factor (BDNF), in combination with the cell proliferation marker bromodeoxyuridine (BrdU), to investigate whether and how the adult forebrain responds to BDNF exposure. The BDNF administration resulted in numerous $\mathrm{BrdU}^{+}$cells, not only in the SVZ lining the lateral ventricle, but also in the striatal and septal parenchyma. Moreover, a high number of BrdU-labeled cells were found in discrete regions of the thalamus and hypothalamus bordering the third ventricle. Approximately $27-42 \%$ of the newly generated cells expressed a neuron-specific marker. Furthermore, we found that the BrdU incorporation was correlated with the level of the high-affinity receptor for BDNF, TrkB. However, the $\mathrm{BrdU}^{+}$cells and $\mathrm{TrkB}^{+}$cells were in non- 
overlapping populations. Collectively, our results underscore the possibility that new neurons can be recruited to replace those lost as a result of disease or injury.

Parts of this work have been published previously in abstract form (Pencea et al., 1999).

\section{MATERIALS AND METHODS}

Implantation of minipumps and administration of BDNF and BrdU. To determine whether the intracerebroventricular infusion of a neurotrophic factor increases the proliferation of new neurons in the adult forebrain, we analyzed the distribution and number of newly generated cells in the forebrain of Sprague Dawley rats, after the administration of BDNF $(n=3)$ compared with that of the control vehicle, $0.1 \mathrm{M}$ PBS, given alone $(n=3)$. The adult rats, weighing $220-250 \mathrm{gm}$, were anesthetized with ketamine and implanted with an osmotic minipump (Alzet 2002; Alza Scientific Products, Palo Alto, CA). The cannula was placed in the right lateral ventricle $4.0 \mathrm{~mm}$ deep to the pial surface and $+0.0 \mathrm{~mm}$ anteroposterior relative to bregma and $1.8 \mathrm{~mm}$ lateral to the midline. Each rat was infused for $12 \mathrm{~d}$ with $12 \mu \mathrm{l} / \mathrm{d}$ of either human recombinant BDNF dissolved in $0.1 \mathrm{~m}$ PBS $(1 \mu \mathrm{g} / \mathrm{ml})$ (Regeneron Pharmaceuticals, Tarrytown, NY) or PBS only. To label the newly generated cells in the BDNF- or vehicle-inf used brains, the cell proliferation marker BrdU was delivered at the same rate $(12 \mu \mathrm{g} / \mathrm{d})$ and through the same minipump as the BDNF or PBS. After the cessation of the infusion of BDNF and BrdU or PBS and BrdU, the cannula was left in the lateral ventricle, and the animals were allowed to survive another $16 \mathrm{~d}$ before perfusion (Fig. $1)$. We also compared the distribution and phenotype of the newly generated cells after the intracerebroventricular infusion of BDNF and $\mathrm{BrdU}$ or PBS and BrdU to that in animals that received only daily intraperitoneal injections of $\mathrm{BrdU}(5 \mathrm{mg} / \mathrm{ml}$ in $0.0007 \mathrm{~N} \mathrm{NaOH}$ saline, 50 $\mathrm{mg} / \mathrm{kg}$ ) for $12 \mathrm{~d}$.

Tissue processing and immunohistochemistry. Sixteen days after the cessation of the intracerebroventricular BDNF and BrdU, PBS and $\mathrm{BrdU}$, or intraperitoneal BrdU, the animals were anesthetized with pentobarbital $(50 \mathrm{mg} / \mathrm{kg})$ and perfused transcardially with heparanized saline ( $5 \mathrm{U}$ of heparin per milliliter of $0.9 \% \mathrm{NaCl}$ ), followed by $4 \%$ paraformaldehyde in $0.1 \mathrm{M}$ phosphate buffer, $\mathrm{pH}$ 7.4. Brains were cryoprotected with $30 \%$ sucrose in $0.1 \mathrm{M}$ phosphate buffer, $\mathrm{pH} 7.2$, embedded in Tissue-Tek OCT compound (Sakura Finetek, Torrance, CA), and sectioned on a cryostat in the coronal plane at $20 \mu \mathrm{m}$.

To reveal newly generated BrdU-positive cells, the sections were incubated for $30 \mathrm{~min}$ in $1 \mathrm{~N} \mathrm{HCl}$ at $60^{\circ} \mathrm{C}$ to denature the DNA. Subsequently, the sections were incubated first in blocking serum (10\% normal goat serum in $0.1 \mathrm{M}$ phosphate buffer containing $0.02 \%$ Triton $\mathrm{X}-100, \mathrm{pH}$ 7.4), abbreviated NGS for $1 \mathrm{hr}$, and then for $48 \mathrm{hr}$ with a 1:200 dilution of a mouse IgG anti-BrdU (Accurate Chemicals, Westbury, NY) in NGS. For fluorescent visualization of BrdU-labeled cells, the sections were incubated for $1 \mathrm{hr}$ at room temperature in a rhodamine-conjugated goat anti-rat secondary antibody (1:200 dilution).

Some sections were processed to visualize only BrdU-labeled cells, whereas others were double-labeled with anti-BrdU, as well as an antibody to a cell type-specific marker to determine the phenotype of the newly generated cells. To identify neurons, we used the antibody TuJ1 (1:400) (Covance, Richmond, CA), a mouse polyclonal IgG that recognizes neuron-specific $\beta$ III-tubulin (Lee et al., 1990) usually expressed by immature neurons, or a monoclonal antibody to microtubule-associated protein-2 (MAP-2) (1:200; Roche Products, Indianapolis, IN), which recognizes more differentiated neurons (Bernhardt et al., 1985; Johnson and Jope, 1992). We also used a polyclonal antibody to glial fibrillary acidic protein (GFAP) (1:500 dilution; Dako, Glostrup, Denmark) (Bignami et al., 1972) to identify astrocytes and either a mouse monoclonal antibody to galactocerebrosidase (GalC) (gift from Dr. Rao, University of Utah, Salt Lake City, UT) at a 1:200 dilution (Ranscht et al., 1982, 1987) or mouse monoclonal anti-myelin proteolipid protein (PLP) (Chemicon, Temecula, CA) at a 1:200 dilution (Cheng et al., 1998) to identify oligodendrocytes. As a marker for undifferentiated cells, a mouse monoclonal antibody to the intermediate filament protein nestin (Hockfield and McKay, 1985; Frederiksen and McKay, 1988; Lendahl and McKay, 1990) was used as an undiluted supernatant (Developmental Studies Hybridoma Bank, Iowa City, IA). In addition, to analyze the expression pattern of TrkB, the high-affinity tyrosine kinase receptor for BDNF, some sections were also incubated with anti-TrkB ${ }_{606-619}$, a polyclonal antibody that recognizes the intracellular domain of the fulllength rat TrkB (amino acids 606-619) (gift from Dr. S. Feinstein,
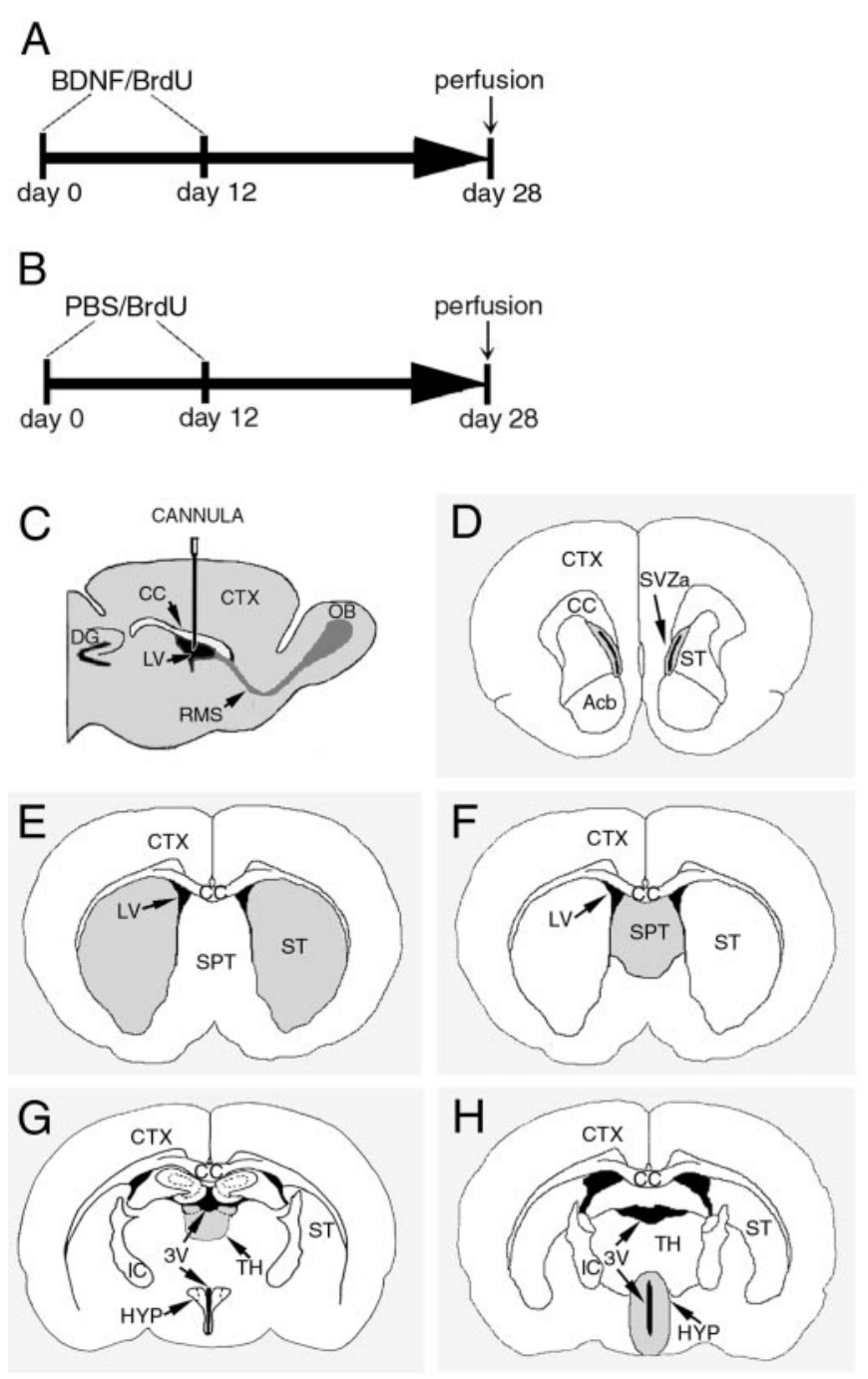

Figure 1. Illustration of the intraventricular infusion site, time course of delivery of BDNF or PBS in conjunction with BrdU, and structures analyzed for the distribution and phenotype of BrdU-labeled cells. $A, B$, In both experimental BDNF-infused (12 $\mu \mathrm{g} / \mathrm{d})$ and control PBS-infused animals, an osmotic minipump was used for continuous delivery of the growth factor or vehicle into the lateral ventricle, at a rate of $5 \mu \mathrm{l} / \mathrm{hr}$ for $12 \mathrm{~d}$. The animals were concurrently inf used with BrdU through the same minipump to label dividing cells. The animals were perfused $16 \mathrm{~d}$ after cessation of the BDNF or PBS infusate. $C$, A diagram of a parasagittal section of the adult rat brain demonstrating the placement in the right lateral ventricle of the cannula used to infuse the BDNF, or PBS, in conjunction with BrdU. $D-H$, Drawings of representative coronal sections of the adult rat brain at different anteroposterior levels, designating the structures quantitatively analyzed after the intraventricular administration of BDNF or PBS. The diagrams demonstrate that each structure analyzed (gray) for the presence of newly generated $\mathrm{BrdU}^{+}$cells is adjacent to the lateral or third ventricle. The anterior part of the subventricular zone $(D)$, striatum $(E)$, and septum $(F)$ surround the lateral ventricle, whereas the thalamus $(G)$ and hypothalamus $(H)$ are adjacent to the third ventricle. Note that, in $G$ and $H$, the third ventricle is transected both ventrally and dorsally. $3 \mathrm{~V}$, Third ventricle; $A c b$, nucleus accumbens; $C C$, corpus callosum; $C T X$, cerebral cortex; $D G$, dentate gyrus; $H Y P$, hypothalamus; $I C$, internal capsule; $L V$, lateral ventricle; $O B$, olfactory bulb; $R M S$, rostral migratory stream; $S P T$, septum; $S T$, striatum; $S V Z a$, anterior part of the subventricular zone; $T H$, thalamus.

University of California, Santa Barbara, CA) at a 1:25 dilution. For fluorescent visualization of all cell type-specific antibodies and antiTrkB, fluorescein-conjugated secondary antibodies were used at a 1:200 dilution. All secondary antibodies were from Jackson ImmunoResearch 
(West Grove, PA). The slides were coverslipped with VectaShield (Vector Laboratories, Burlingame, CA) and viewed using a Zeiss (Oberkochen, Germany) Axiophot fluorescent microscope equipped with rhodamine and fluorescein filters, as well as a dual filter for visualizing rhodamine and fluorescein fluorescence simultaneously. For confirmation of the phenotype of individual $\mathrm{BrdU}^{+}$cells, sections were also viewed using a confocal scanning laser microscope (Zeiss Axioplan equipped with LSM 510). To reveal the cytoarchitecture of the structures analyzed, some sections were dehydrated in ethanol, counterstained with cresyl violet, rehydrated, and coverslipped with DPX (BDH Laboratory Supplies, Poole, UK). All microscopic images were processed using Adobe Photoshop (Adobe Systems, Mountainview, CA).

Quantitative analyses. The density of BrdU-labeled cells, expressed as cells per cubic millimeter, was determined in the striatum, septum, thalamus, and hypothalamus, in both the BDNF-infused and PBSinfused brains. We selected for comparisons corresponding coronal sections exhibiting the same cytoarchitectonic features, determined using the rat atlas of Paxinos and Watson (1982), in all of the BDNF- and PBS-infused brains. This allowed cells to be counted in coronal sections at comparable rostrocaudal positions. The counts were made, using a $40 \times$ objective, by placing an optical grid (field size, $250 \times 250 \mu \mathrm{m}$ ) starting from the wall of the lateral or third ventricle and proceeding into the parenchyma until $\mathrm{BrdU}^{+}$cells were no longer detectable. The density of BrdU-labeled cells was calculated for each structure analyzed in every animal, and statistical analyses were performed using the Student's $t$ test (IBM Statistica; StatSoft Inc., Tulsa, OK).

The number of double-labeled BrdU ${ }^{+}-\mathrm{TuJ} 1^{+}$and $\mathrm{BrdU}^{+}-\mathrm{GFAP}^{+}$ cells in the striatum, septum, hypothalamus, and subventricular zone surrounding the lateral ventricle was counted when viewed with a conventional or confocal microscope in at least three sections per brain. In each animal, the phenotype of 330-850 striatal cells, 200-900 septal cells, 200-1200 hypothalamic cells, and 600-2500 subventricular cells was analyzed. The counts of double-labeled cells were analyzed statistically using two-way and one-way ANOVA.

To compare the nuclear diameter of the newly generated cells in the striatum, septum, hypothalamus, and thalamus, in BDNF- and PBSinfused animals, 25-40 cells per structure were analyzed in each animal. The maximum nuclear diameter was measured using IP Lab Scientific Processing (Scanalytics Inc., Fairfax, VA), and an average nuclear diameter was calculated for each structure in each animal. These means were then combined to determine the average diameter of newly generated cells in the parenchyma of the BDNF- and PBSinfused brains. In the same sections, $\sim 250 \mathrm{BrdU}^{+}$cells per animal were analyzed with IP Lab Scientific Processing to determine the percentage of newly generated cells present in pairs. The cells were considered to form a pair if their $\mathrm{BrdU}^{+}$nuclei were adjacent $(<3 \mu \mathrm{m}$ apart) to one another.

\section{RESULTS}

We examined the effect of intracerebroventricular administration of BDNF on the distribution and phenotype of newly generated cells in the adult forebrain. BDNF or PBS (control) was inf used continuously for $12 \mathrm{~d}$ into the right lateral ventricle of adult rats (Fig. $1 A, B)$. A steady-state level of BDNF is achieved by intracerebroventricular infusion within 3 d (Anderson et al., 1995). To label the newly generated cells, the cell proliferation marker BrdU was delivered by intracerebroventricular infusion concurrently with the BDNF (BDNF-BrdU) or PBS (PBS-BrdU) (Fig. $1 A, B)$. The animals were perfused $16 \mathrm{~d}$ after BDNF or PBS withdrawal (day 28) (Fig. $1 A, B$ ) to permit newly generated cells to integrate in the host brain. The distribution and phenotype of the newly generated $\mathrm{BrdU}^{+}$cells were analyzed along the rostrocaudal extent of the lateral and third ventricles (Fig. $1 D-H$ ). A third group of animals received daily BrdU intraperitoneal injections for $12 \mathrm{~d}$, without any intracerebroventricular infusion. These animals were also perfused $16 \mathrm{~d}$ after the last BrdU injection.

\section{Newly generated cells appear in distinct regions surrounding the lateral and third ventricles after combined intracerebroventricular administration of BDNF and BrdU}

To determine which regions surrounding the lateral and third ventricles have the capacity to produce new cells in response to BDNF infusion into the adult lateral ventricle, we systematically analyzed the distribution of $\mathrm{BrdU}^{+}$cells in the subventricular zone and parenchyma along the rostrocaudal extent of the forebrain. Our analysis revealed that newly generated cells were present surrounding the lateral ventricle on the infused side but not on the contralateral side, indicating that the BDNF-BrdU did not diffuse contralaterally. An unexpected finding was that, in addition to newly generated cells along the rostrocaudal extent of the rostral migratory stream (RMS) as reported previously (Zigova et al., 1998), we also detected newly generated cells: (1) in other regions of the SVZ immediately surrounding the lateral ventricle, (2) in the parenchyma adjacent to the lateral ventricle (Fig. 2A), and (3) in the parenchyma of specific structures surrounding the third ventricle, in which cell proliferation has not been described previously (Fig. $2 B$ ). In particular, newly generated cells were visualized in the striatum, septum, corpus callosum, and cerebral cortex, as well as in the thalamus and hypothalamus (Figs. 2, 3). The presence of newly generated cells in specific parts of the thalamus and hypothalamus surrounding the third ventricle suggests that BDNF-BrdU may have flowed caudally from the infused lateral ventricle into the third ventricle.

To determine whether there was a relationship between the parenchymal structures in which the $\mathrm{BrdU}^{+}$cells were found and the morphology of the newly generated cells, in addition to double-labeling with BrdU and cell type-specific markers (as described below), we used the nuclear shape and diameter of the labeled cells as a way to compare the diversity of labeled cells in different regions of the forebrain. In the BDNF-infused brains, the nuclear diameter and morphology of the newly generated cells varied according to the regions in which they were located, and the largest mean nuclear diameter (range of 9.22-9.53 $\mu \mathrm{m}$ ) was found in the striatum. The nuclei of the $\mathrm{BrdU}^{+}$cells in the striatum and septum tended to be round, whereas the nuclei in the hypothalamus and thalamus were usually elongated. These results indicate that a diversity of cell types was generated as a function of the location of the cells. However, despite this diversity, in all of the structures analyzed, the $\mathrm{BrdU}^{+}$cells were present frequently in close apposition to each other, such that they were aggregated in pairs (Fig. 4). In the parenchymal structures containing $\mathrm{BrdU}^{+}$cells, the percentage of paired cells was relatively uniform within a given structure, varying from an average of $22 \%$ in the hypothalamus to $37 \%$ in the striatum. The presence of pairs of $\mathrm{BrdU}^{+}$cells may indicate that cell division occurs in situ in the parenchyma.

Our analysis showed that the number of newly generated cells in the brains of rats infused with PBS-BrdU was substantially lower than in the brains infused with BDNF-BrdU, although the distribution of the newly generated cells was similar in both sets of animals (Figs. 3, 5). However, the distribution of $\mathrm{BrdU}^{+}$cells after intracerebroventricular infusion of BrdU combined with either BDNF or PBS differs from that observed after only intraperitoneal administration of BrdU. In the animals that received intraperitoneal injections, the BrdU-labeling was present mainly in the subventricular zone adjacent to the lateral ventricle, with just a few BrdU ${ }^{+}$cells in the parenchyma surrounding the lateral and third ventricles. The pronounced discrepancy between the 

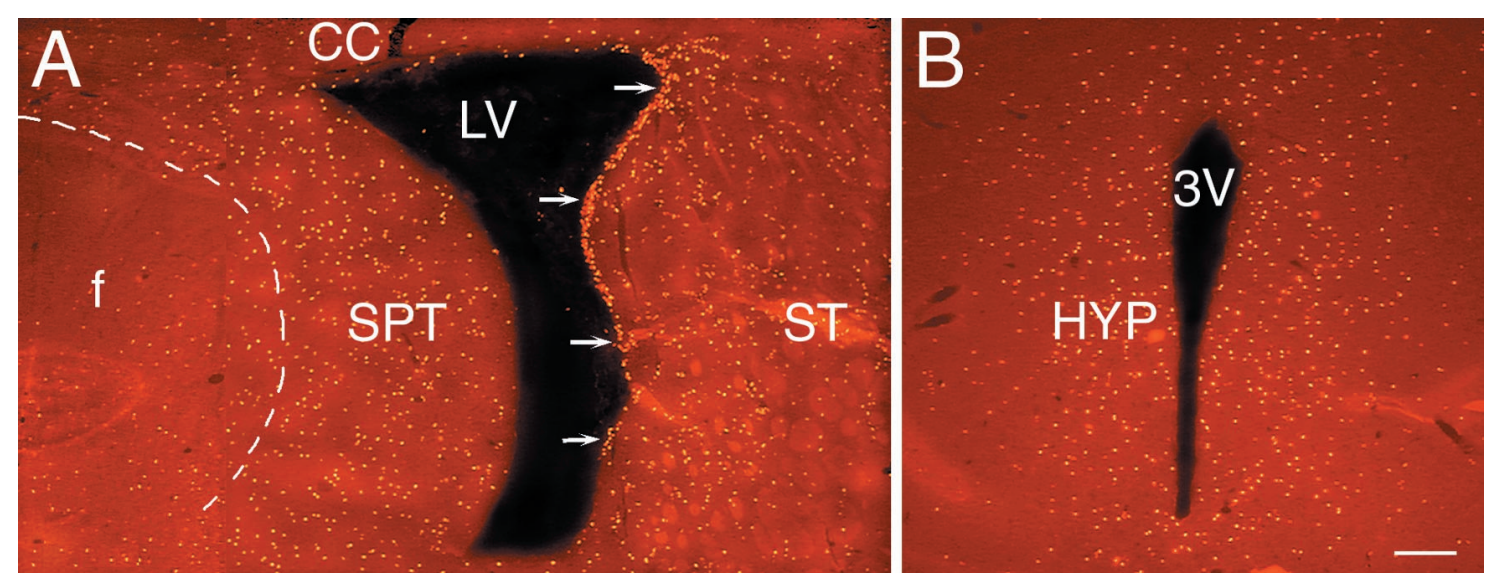

Figure 2. The distribution of newly generated cells in the parenchyma surrounding the lateral and third ventricles after the coinfusion of BDNF and BrdU into the lateral ventricle of an adult rat brain. The newly generated cells (bright orange) are identified in $20 \mu \mathrm{m}$ coronal sections with an antibody to $\mathrm{BrdU}$ and visualized with a rhodamine-conjugated secondary antibody. $A$, A representative fluorescent photomicrograph demonstrating BrdU ${ }^{+}$cells in the parenchyma surrounding the inf used lateral ventricle $16 \mathrm{~d}$ after a $12 \mathrm{~d}$ inf usion of BDNF-BrdU. The striatal SVZ (arrows) has numerous BrdU ${ }^{+}$ cells, whereas the rest of the SVZ, including that lining the septum, is almost devoid of newly generated cells. Moreover, the dorsal half of the striatal SVZ appears thicker than the ventral part. The distribution of the $\mathrm{BrdU}^{+}$cells in the striatal parenchyma exhibits a medial to lateral gradient, with the number of $\mathrm{BrdU}^{+}$cells decreasing as a function of distance from the lateral ventricle. The distribution of BrdU ${ }^{+}$cells in the septal parenchyma is more homogenous, although there is a relatively sharp decrease in the number of $\mathrm{BrdU}^{+}$cells at the border between septum and fornix (dashed line). Note that, on both sides of the lateral ventricle, the $\mathrm{BrdU}^{+}$cells extend more than a few hundred micrometers into the parenchyma. A small number of the newly generated cells can also be observed in the corpus callosum overlying the lateral ventricle. The midline of the section is approximately at the left edge of the photomicrograph. $B$, A representative fluorescent photomicrograph showing $\mathrm{BrdU}^{+}$cells in the parenchyma surrounding the third ventricle of a BDNF-infused brain. In the hypothalamus, the newly generated cells extend bilaterally at least a few hundred micrometers into the parenchyma, and their distribution is relatively homogenous. Similar to the septal SVZ (shown in $A$ ), the hypothalamic ventricular lining is devoid of BrdU ${ }^{+}$cells. $3 V$, Third ventricle; $C C$, corpus callosum; $H Y P$, hypothalamus; $L V$, lateral ventricle; $S P T$, septum; $S T$, striatum. Scale bar, $100 \mu \mathrm{m}$.

distribution of BrdU labeling in the brains of the intracerebroventricular infused and intraperitoneal injected animals underscores the limited ongoing proliferation that ordinarily occurs in the parenchyma versus the subventricular zone of the adult brain.

\section{The pattern of distribution of $\mathrm{BrdU}^{+}$cells in the SVZ and parenchyma of the forebrain after intracerebroventricular administration of BDNF and BrdU}

Our data indicated that there was a differential response to BDNF infusion in different regions along the ventricular lumen. In the SVZ lining the striatum, there was a prominent dorsal to ventral gradient of $\mathrm{BrdU}^{+}$cells (Fig. $2 \mathrm{~A}$ ). In the dorsal aspect of the striatal $\mathrm{SVZ}, \mathrm{BrdU}^{+}$cells formed a band multiple cell layers thick, whereas the ventral part of the striatal SVZ was considerably thinner and contained widely dispersed $\mathrm{BrdU}^{+}$cells. Moreover, the $\mathrm{BrdU}^{+}$cells in the dorsal aspect of the striatal SVZ often occurred in clusters (Fig. 3D), suggesting that there were "hot spots" of proliferation around the lateral ventricle, similar to those described in the telencephalon of the adult canary (AlvarezBuylla et al., 1990). The gradient in the BrdU labeling of the SVZ parallels the differences ordinarily observed in the relative thickness and density of the SVZ, as described by Chiasson et al. (1999).

In the parenchyma of each structure containing $\mathrm{BrdU}^{+}$cells, the density of the newly generated cells declines as a function of distance from the ventricular wall (Fig. 4). However, there was no apparent correlation between the extent and thickness of the SVZ and the number of newly generated cells present in the adjoining parenchyma. In some structures, such as the septum, there were numerous $\mathrm{BrdU}^{+}$cells in the parenchyma, up to $1 \mathrm{~mm}$ from the ventricular wall (Figs. $2 A, 3 F, 5 B$ ), although there was only marginal labeling of the SVZ. Conversely, in some regions containing a prominent SVZ, such as the striatum, there was a high density of $\mathrm{BrdU}^{+}$cells in the SVZ adjacent to the lateral ventricle (Figs. $2 A, 3 D$ ). Moreover, there were numerous $\mathrm{BrdU}^{+}$ cells in the adjacent striatal parenchyma, up to $2 \mathrm{~mm}$ away from the lateral ventricle (Figs. $2 A, 3 D, 5 A$ ). In addition, a considerable number of $\mathrm{BrdU}^{+}$cells were observed in the parenchyma of the thalamus and hypothalamus surrounding the third ventricle, despite the absence of a distinguishable SVZ (Figs. 2B, 3H,J, 5C). Thus, the extent of the SVZ is not the only determining factor for the production of new cells in the adult forebrain.

The $\mathrm{BrdU}^{+}$cells in the parenchyma were not evenly distributed. Rather, the distribution of $\mathrm{BrdU}^{+}$cells was restricted by boundaries between and within structures of the forebrain, similar to the restriction of newly generated cells in the RMS (Luskin, 1993; Zigova et al., 1996, 1998). For example, although the $\mathrm{BrdU}^{+}$cells in the septum on the infused side were widespread and numerous, they appeared to "avoid" the midline fimbria fornix and to form a dorsal and a ventral stream around the fimbria (Fig. $2 A$ ). The presence of $\mathrm{BrdU}^{+}$cells in the septum adjacent to the uninfused lateral ventricle, combined with the absence of $\mathrm{BrdU}^{+}$cells in the SVZ and striatum also lining the uninfused ventricle, suggests that some cells generated on the infused side may have migrated across the midline to the contralateral septum. Alternatively, BrdU may have directly diff used across the midline in which it then became incorporated in the septal cells on the contralateral side. The labeling pattern observed in the septum indicates that the distribution of $\mathrm{BrdU}^{+}$ cells is neither the result of the random migration of $\mathrm{BrdU}^{+}$cells nor the effect of the passive diffusion of the BDNF-BrdU.

Prominent differences in the extent of BrdU incorporation were also observed surrounding the third ventricle. In particular, although there were numerous $\mathrm{BrdU}^{+}$cells in the habenular nucleus of the thalamus, there were no $\mathrm{BrdU}^{+}$cells in the part of the dentate gyrus immediately adjacent to the third ventricle (Fig. 

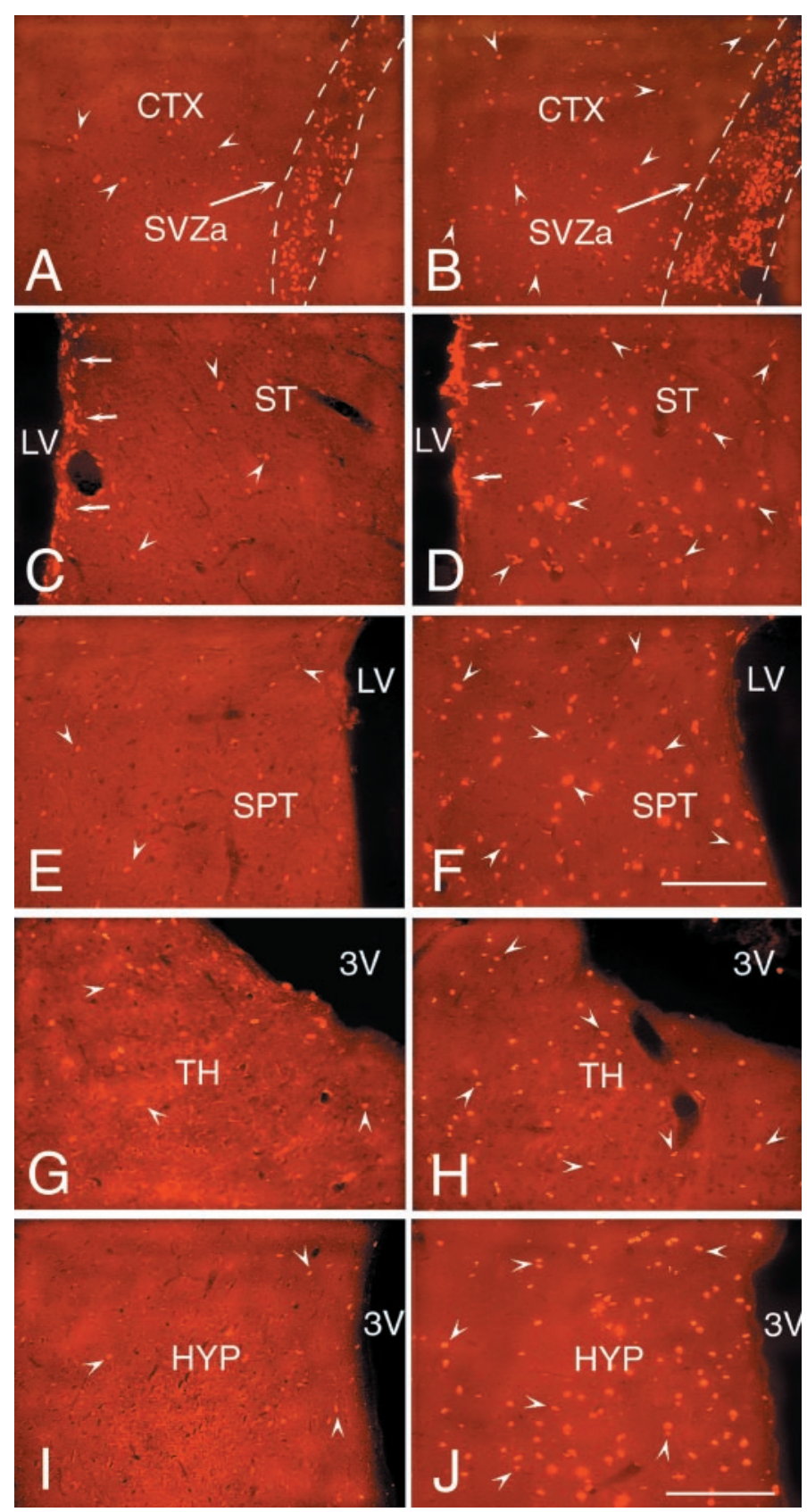

Figure 3. A comparison of the number and distribution of the newly generated cells in forebrain structures surrounding the lateral and third ventricles after the intraventricular coinfusion of BDNF and BrdU or PBS and BrdU. The newly generated BrdU-positive cells (bright orange) were identified in $20 \mu \mathrm{m}$ coronal sections with an antibody to BrdU and visualized with a secondary antibody conjugated to rhodamine. $A, B$, Representative fluorescent photomicrographs of infused hemispheres showing $\mathrm{BrdU}^{+}$cells in the anterior part of the subventricular zone and the adjacent frontal cortex after infusion of PBS-BrdU $(A)$ or BDNF$\operatorname{BrdU}(B)$ into the ipsilateral lateral ventricle. After BDNF infusion, the SVZa $(B)$ is expanded in diameter relative to the SVZa of the PBSinfused brain $(A)$. Moreover, after BDNF infusion $(B)$, the number of newly generated cells (e.g., arrowheads) present in the frontal cortex surrounding the SVZa is much higher than that observed in the PBSinfused brain $(A)$. $C, D$, Representative fluorescent photomicrographs of infused hemispheres demonstrating the number of $\mathrm{BrdU}^{+}$cells in the striatum in brains infused with PBS $(C)$ or with BDNF $(D)$. After BDNF or $\mathrm{PBS}$ infusion, $\mathrm{BrdU}^{+}$cells are dispersed throughout the striatal parenchyma, although there are substantially fewer new cells in the PBS-infused brain $(C)$. Moreover, in the BDNF-infused brain $(D)$ compared with the PBS-infused brain $(C)$, the number of newly generated

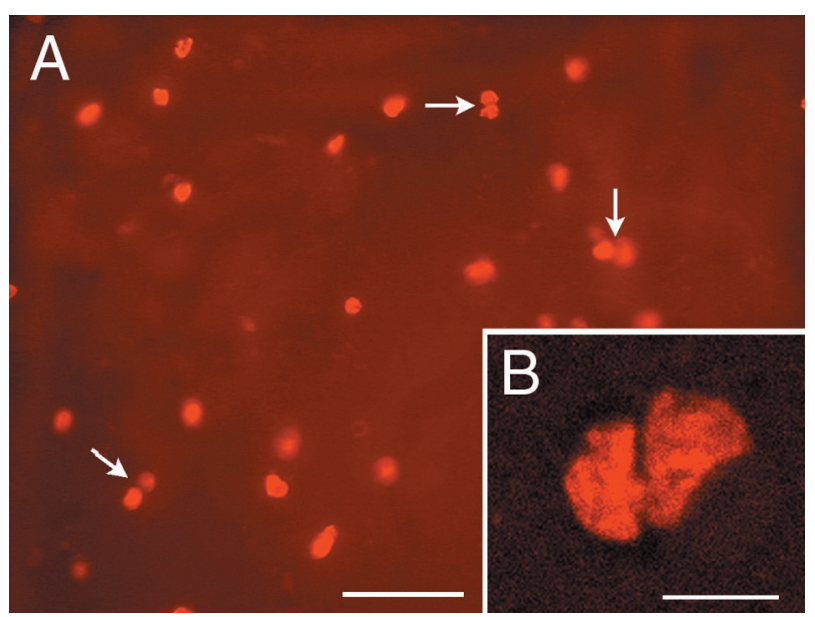

Figure 4. Pairs of newly generated cells in the parenchyma of the striatum after intraventricular infusion of BDNF. $A$, A representative fluorescent photomicrograph of a $20 \mu \mathrm{m}$ coronal section demonstrating that, $16 \mathrm{~d}$ after withdrawal of a $12 \mathrm{~d}$ infusion of BDNF-BrdU, a high proportion of the newly generated cells within the striatal parenchyma occur in pairs. The cleavage plane between pairs of cells (e.g., arrows) appears random, with no preferential orientation relative to the ventricular surface. Midline is to the right, and dorsal is up. $B$, A representative photomicrograph of the septal parenchyma, viewed with confocal microscopy, showing a pair of newly generated $\mathrm{BrdU}^{+}$cells. The short distance $(<2 \mu \mathrm{m})$ between the pairs of $\mathrm{BrdU}^{+}$nuclei combined with the high frequency of pairs (shown in $A$ ) suggests that, after BDNF administration, cell division may occur in situ. Scale bars: $A, 50 \mu \mathrm{m} ; B, 10 \mu \mathrm{m}$.

$6 B)$. However, after infusion of BDNF, there were newly generated cells in the subgranular layer of the dentate gyrus, as has been described previously in the normal brain (Altman and Das, 1965; Schlessinger et al., 1975; Kaplan and Bell, 1984; Kuhn et al., 1996; Palmer et al., 1997). The restriction of BrdU labeling to discrete regions surrounding the third ventricle is further illustrated by the paucity of $\mathrm{BrdU}^{+}$cells in other thalamic nuclei adjacent to the habenula, although some of them are also adjacent to the third ventricle (data not shown).

The hypothalamus, another structure bordering the third ventricle, also exhibits a well defined pattern of BrdU labeling after

$\leftarrow$

cells in the striatal SVZ is higher, and more of these cells tend to occur in clusters. $E, F$, Representative fluorescent photomicrographs of infused hemispheres demonstrating the newly generated cells in the septum adjacent to the infused lateral ventricle. The number of $\mathrm{BrdU}^{+}$cells (e.g., arrowheads) in the septal parenchyma of the BDNF-infused brain $(F)$ is much higher than the number of labeled cells in the PBS-infused brain $(E)$. In both cases, however, the septal SVZ is almost devoid of $\mathrm{BrdU}^{+}$ cells. $G, H$, Representative fluorescent photomicrographs showing BrdUpositive cells in the thalamus, adjacent to the dorsal lumen of the third ventricle, after the infusion of $\mathrm{PBS}-\mathrm{BrdU}(G)$ or $\mathrm{BDNF}-\mathrm{BrdU}(H)$. The number of $\mathrm{BrdU}^{+}$cells (e.g., arrowheads) present in the thalamic parenchyma of the BDNF-infused brain $(H)$ is higher than the number observed in the PBS-infused brain $(G)$. In both sections, there are a few $\mathrm{BrdU}^{+}$cells lining the wall of the third ventricle. $I, J$, Representative fluorescent photomicrographs demonstrating the relative number of $\mathrm{BrdU}^{+}$cells in the hypothalamus of the PBS-infused $(I)$ compared with BDNF-infused $(J)$ brain. After BDNF infusion $(J)$, numerous $\mathrm{BrdU}^{+}$ cells (e.g., arrowheads) are dispersed throughout the hypothalamic parenchyma, whereas after the PBS infusion (I), fewer $\mathrm{BrdU}^{+}$cells (e.g., arrowheads) are present. Note that very few $\mathrm{BrdU}^{+}$cells line the third ventricle in the sections from both the BDNF-infused and PBS-infused brains. $3 V$, Third ventricle; $C T X$, frontal cortex; $L V$, lateral ventricle; $H Y P$, hypothalamus; SPT, septum; ST, striatum; TH, thalamus. Scale bars, $100 \mu \mathrm{m}$. 
A

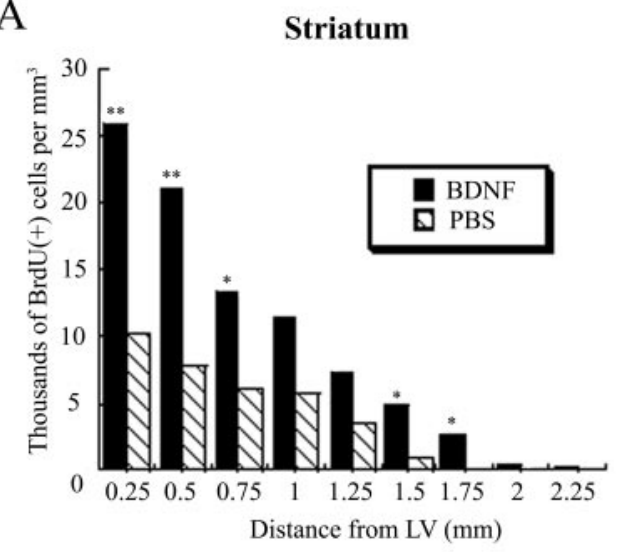

B

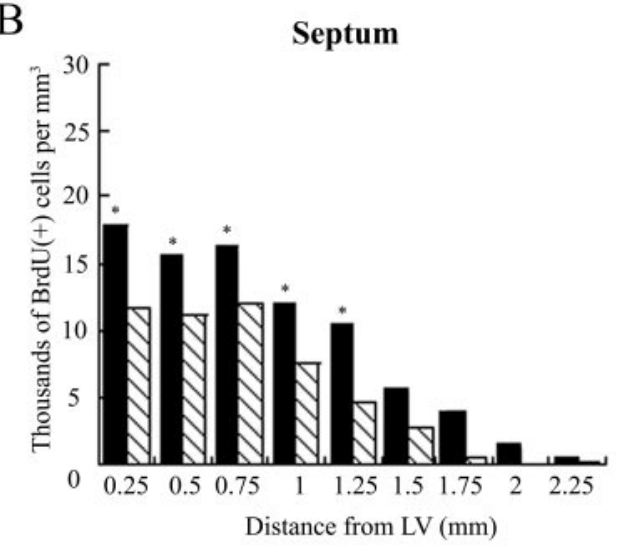

$\mathrm{C}$

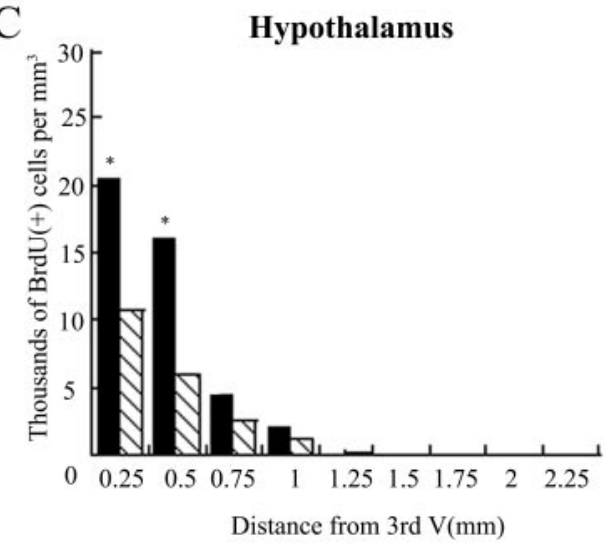

Figure 5. Density of newly generated $\mathrm{BrdU}^{+}$cells in the striatum, septum, and hypothalamus after BDNF infusion relative to PBS infusion. For each structure analyzed, the gradient of the cell density is plotted from the wall of the ventricle (corresponding to the origin of axes) to 2.25 $\mathrm{mm}$ into the parenchyma. $A$, In the striatum, adjacent to the lateral ventricle, the density of the $\mathrm{BrdU}^{+}$cells is two to three times higher after BDNF inf usion than after PBS inf usion, and in both cases the cell density declines gradually as a function of distance from the ventricular wall. Nevertheless, the newly generated cells extend farther into the parenchyma after BDNF infusion compared with PBS infusion. $B$, At each position in the septum, the cell density is $\sim 1.5$ times higher after BDNF inf usion than after PBS infusion. In both groups, the cell density remains relatively constant in the septal parenchyma $(\sim 0.75 \mathrm{~mm}$ from the ventricular wall) and then decreases gradually in the fimbria fornix. $C$, In the proximal $0.5 \mathrm{~mm}$ adjacent to the third ventricle, the cell density in the hypothalamus is more than two times higher after BDNF administration than after PBS infusion. The number of the newly generated cells declines steeply beyond the hypothalamic border in both the BDNF- and PBSinf used brains. * $p<0.05$; * $p<0.005$.
BDNF infusion. Whereas in the rostral hypothalamus there was a relatively uniform density of $\mathrm{BrdU}^{+}$cells surrounding the third ventricle (Fig. 2B), more caudally, the newly generated cells were concentrated in particular hypothalamic nuclei. For example, there was a relatively high density of $\mathrm{BrdU}^{+}$cells in the parvocellular region of the paraventricular nucleus, although it is displaced from the wall of the third ventricle (Fig. $6 F$ ). Conversely, the periventricular nucleus immediately surrounding the third ventricle has a comparatively low number of $\mathrm{BrdU}^{+}$cells. Together, the pattern of BrdU labeling in the hypothalamus suggests that regions presumably exposed to the highest concentration of BDNF (e.g., those closest to the ventricular lumen) do not necessarily contain the highest density of newly generated $\mathrm{BrdU}^{+}$ cells.

TrkB expression in the forebrain parenchyma of BDNFinfused brains correlates with sites of cell proliferation

To determine the correlation between the increased cell proliferation after intracerebroventricular infusion of BDNF and the expression of TrkB, the high-affinity receptor for BDNF, we analyzed the relationship between the BrdU incorporation and the pattern of the full-length TrkB expression in the structures surrounding the lateral and third ventricles. In a previous study (Zigova et al., 1998), we found that the anterior part of the SVZ (SVZa) and the RMS of BDNF-inf used adult brains contained a higher number of $\mathrm{BrdU}^{+}$cells and expressed higher levels of TrkB compared with the surrounding areas. In the present study, a similar correlation was observed in the areas surrounding the lateral (data not shown) and third (Fig. 6) ventricles. This correlation, such that the extent of BrdU incorporation and TrkB expression parallel each other, can be observed in the regions of the hypothalamus examined. There were numerous $\mathrm{BrdU}^{+}$cells and a high level of TrkB expression in the paraventricular nucleus of the hypothalamus, whereas in the periventricular nucleus, the numbers of BrdU-labeled cells and TrkB expression were both low (Fig. $6 E-G)$. Nevertheless, TrkB expression is not sufficient for cell proliferation. For example, whereas TrkB is expressed at a uniformly high level throughout the habenular nucleus (Fig. $6 D), \mathrm{BrdU}^{+}$cells are much more numerous along the medial edge (Fig. 6B). This disparity cannot be accounted for by the differences in BDNF exposure, because the dorsal edge of the habenular nucleus, which has lower BrdU incorporation, also faces the third ventricle.

To investigate whether the TrkB expression was influenced by the inf usion of BDNF, we compared the pattern of TrkB expression in the BDNF-infused hemispheres versus uninf used hemispheres or PBS-infused hemispheres. The levels of TrkB expression in different structures of the BDNF-infused hemispheres were similar to those in the contralateral uninf used hemispheres and in the PBS-infused brains. These findings indicate that the inf usion of BDNF or PBS did not result in an overt change in the level of TrkB expression in the regions containing BrdU ${ }^{+}$cells.

In the regions in which we observed both high levels of TrkB and numerous BrdU-labeled cells, we further investigated whether the cells expressing TrkB were able to incorporate BrdU during the administration of BDNF-BrdU. Our confocal analysis revealed that the full-length TrkB receptor was not expressed by the $\mathrm{BrdU}^{+}$cells in the parenchyma (Fig. 7). Nevertheless, the $\mathrm{TrkB}^{+}$cells were frequently adjacent to the $\mathrm{BrdU}^{+}$cells (Fig. $7 C, D$, insets), suggesting that BDNF may have an indirect effect on the proliferation and/or survival of the newly generated cells (see Discussion). 
Figure 6. The correlation between the distribution of newly generated cells and the expression of TrkB in the parenchyma surrounding the third ventricle. $A-G$, Representative fluorescent photomicrographs of $20 \mu \mathrm{m}$ coronal sections demonstrating the relationship between TrkB expression and BrdU incorporation in structures surrounding the third ventricle, $16 \mathrm{~d}$ after a $12 \mathrm{~d}$ interval of BDNF and BrdU coinf usion. BrdU ${ }^{+}$cells were identified with an antibody to BrdU and visualized by a rhodamine-conjugated secondary antibody $(B, F)$, whereas TrkB expression was detected in adjacent sections with an antibody to TrkB and visualized by a fluorescein-conjugated secondary antibody $(C, D, G)$. The cytoarchitecture of the structures analyzed was visualized by either their pattern of $\mathrm{TuJ} 1$ staining $(A)$ or viewing sections stained with cresyl violet and viewed with a $4^{\prime}, 6^{\prime}$-diamidino-2-phenylindole filter $(E)$. $A-D$, Photomicrographs of the thalamic habenular nucleus and dentate gyrus adjacent to the dorsal lumen of the third ventricle stained with TuJ1 $(A)$, anti-BrdU $(B)$, and anti-TrkB $(C, D)$. The habenular nucleus, with numerous $\mathrm{BrdU}^{+}$cells, has a high level of TrkB expression $(D)$, whereas the cells in the dentate gyrus, overlying the habenula, neither incorporate BrdU $(B)$ nor express TrkB $(D)$. $E-G$, Photomicrographs of the periventricular and paraventricular nuclei of the hypothalamus surrounding the ventral lumen of the third ventricle demonstrating their differential response to BDNF administration. The paraventricular nucleus has a much higher number of newly generated cells than the periventricular nucleus, despite its position farther away from the wall of the third ventricle. The TrkB expression $(G)$ correlates with the level of BrdU expression; it is higher in the paraventricular nucleus than in the periventricular nucleus. The asterisks in $E-G$ designate corresponding regions of the paraventricular nucleus. $3 V$, Third ventricle; $D G$, dentate gyrus; $\mathrm{Hb}$, thalamic habenular nucleus; $\mathrm{Pa}$, paraventricular hypothalamic nucleus; $P e$, periventricular hypothalamic nucleus. Scale bars: $A, B ; 200 \mu \mathrm{m} ; C, D, 50 \mu \mathrm{m} ; E-G, 200 \mu \mathrm{m}$.
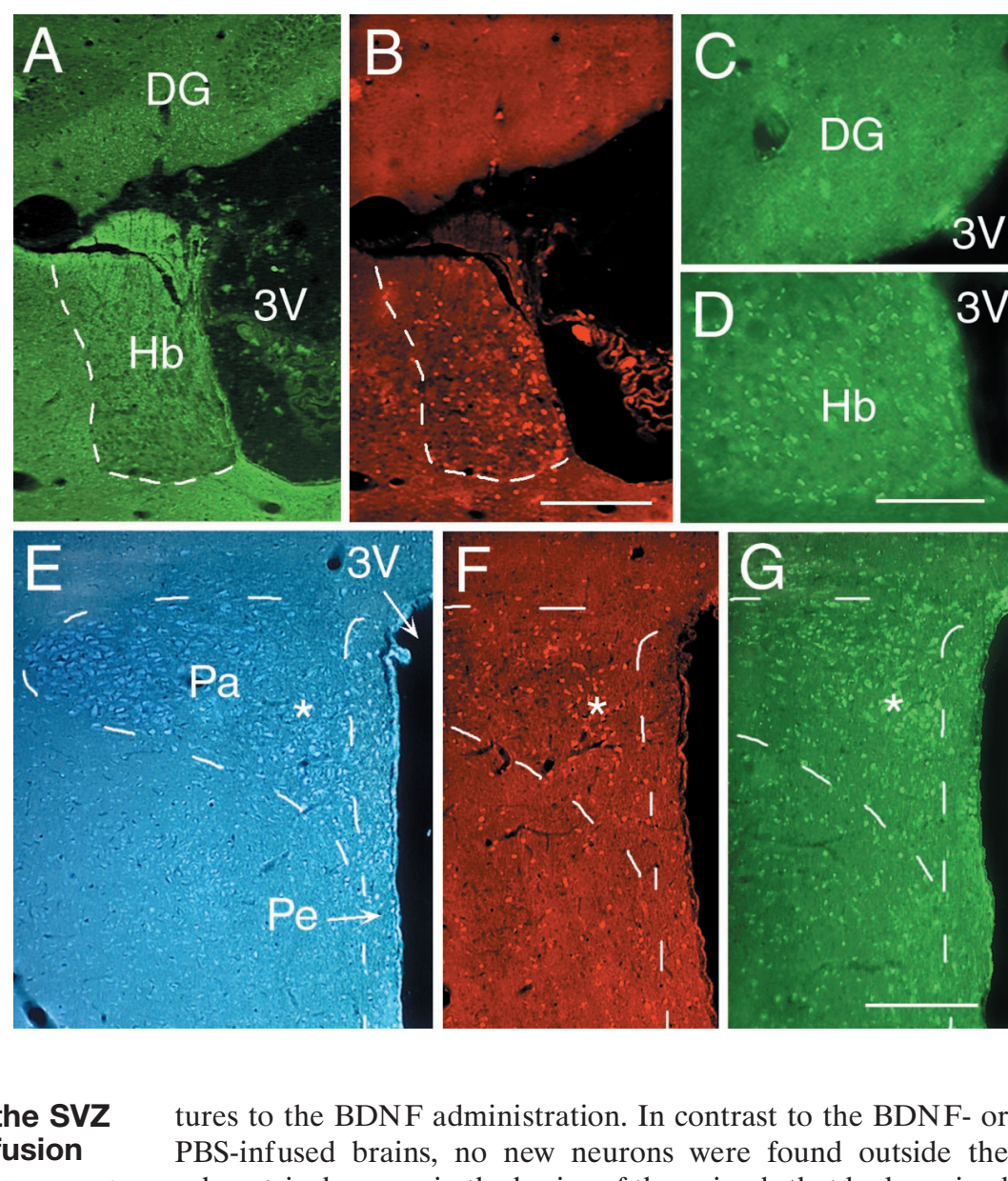

\section{Numerous newly generated neurons appear in the SVZ and parenchyma of the forebrain after BDNF infusion}

We analyzed the phenotype of the $\mathrm{BrdU}^{+}$cells in the SVZ and parenchyma after intracerebroventricular infusion of BDNF to determine what proportion of the newly generated cells were neurons. The phenotype of the newly generated $\mathrm{BrdU}^{+}$cells was identified using cell type-specific markers. In all regions examined, a significant proportion of $\mathrm{BrdU}^{+}$cells colocalized TuJ1 (Fig. 8A-G), an antibody against neuron-specific $\beta$ III-tubulin, expressed by immature neurons (Lee et al., 1990; Easter et al., 1993). The percentage of double-labeled $\mathrm{TuJ} 1^{+}-\mathrm{BrdU}^{+}$cells in the SVZ was $\sim 27 \%$ (Table 1). A similar percentage of the $\mathrm{BrdU}^{+}$ cells in the parenchyma of the striatum and septum were neurons; the percentage was slightly higher $(\sim 42 \%)$ in the hypothalamus (Table 1). In each of the regions containing $\mathrm{TuJ} 1^{+}-\mathrm{BrdU}^{+}$cells, we also observed that a small percentage of the newly generated cells expressed MAP- $2^{+}$, a marker for mature neurons (Bernhardt et al., 1985; Johnson and Jope, 1992) (Fig. 8H-K). This discrepancy between the percentage of $\mathrm{TuJ} 1^{+}$and anti-MAP-2 ${ }^{+}$ cells suggests that the majority of the newly generated neurons may not have sufficiently matured to express MAP-2.

The percentages of the newly generated cells that were $\mathrm{TuJ} 1^{+}$ were similar in the BDNF- and PBS-infused brains in the SVZ, striatum, and septum but not in the hypothalamus, indicating that, in most regions, the in vivo administration of BDNF did not alter the phenotype of the newly generated cells. In all regions, however, the total number of new neurons was significantly higher after BDNF infusion than PBS infusion. In the hypothalamus, there was a higher percentage of newly generated neurons in the BDNF-infused than in the PBS-inf used brains (e.g., $\sim 41 \%$ after BDNF vs $\sim 21 \%$ after PBS), suggesting that the cells of the hypothalamus may respond differently than other forebrain struc- tures to the BDNF administration. In contrast to the BDNF- or PBS-infused brains, no new neurons were found outside the subventricular zone in the brains of the animals that had received only intraperitoneal injections of BrdU (data not shown).

Because the multipotential progenitor cells in the adult SVZ ordinarily give rise to glia (Reynolds et al., 1992; Chiasson et al., 1999), we investigated what percentage of the newly generated $\mathrm{BrdU}^{+}$cells are astrocytes or oligodendrocytes after BDNF infusion. We used an antibody to GFAP to identify astrocytes and antibodies against GalC and PLP to identify oligodendrocytes. In both the BDNF- and PBS-inf used brains, the parenchyma of the striatum (Fig. 9A), septum, and hypothalamus (Fig. 9B) contained a low percentage $(2-7 \%)$ of newly generated $\mathrm{GFAP}^{+}$cells (Table 1). The percentage of $\mathrm{BrdU}^{+}$astrocytes was similar $(\sim 3 \%)$ in the hypothalamus in the BDNF- and PBS-infused brains, whereas in the striatum and septum, the percentage of $\mathrm{BrdU}^{+}$astrocytes was higher in the BDNF-inf used brains (Table 1). In both the BDNFand PBS-infused brains, however, the percentage of newly generated astrocytes was much higher (17-19\%) in the SVZ than in the parenchyma. In each of the areas examined, the percentage of $\mathrm{BrdU}^{+}$oligodendrocytes was negligible and not quantified.

The SVZ of the adult brain contains cells that express the intermediate neurofilament protein nestin, characteristic of undifferentiated neuroepithelial and radial glial cells (Hockfield and McKay, 1985; Lendahl and McKay, 1990). Because nestin ${ }^{+} \mathrm{SVZ}$ cells have the ability to incorporate BrdU and proliferate (Morshead et al., 1994), we sought to determine whether there was an increase in the percentage of nestin ${ }^{+}-\mathrm{BrdU}^{+}$cells after the administration of BDNF. Although we observed a few nestin ${ }^{+}$ cells in the SVZ surrounding the lateral ventricle as well as around the cortical lesion made by the infusion catheter, they were absent from the parenchyma. Moreover, only a low percent- 


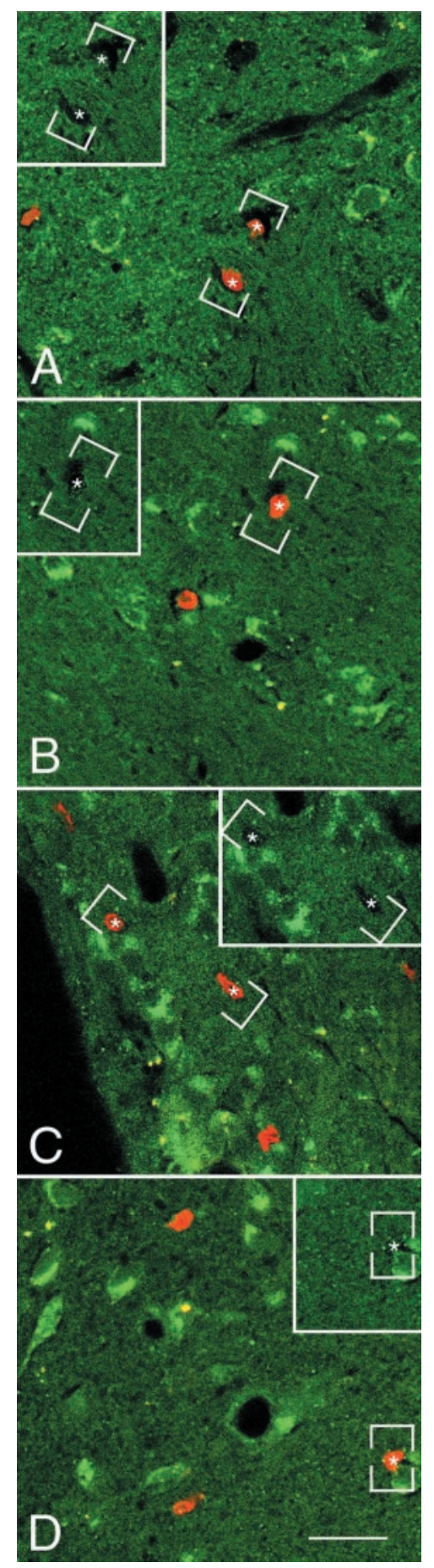

Figure 7. The newly generated cells in the parenchyma of the adult rat forebrain do not express TrkB receptor after coinfusion of BDNF and BrdU. $A-D$, Representative fluorescent photomicrographs of coronal sections, captured by confocal microscopy, showing the distribution of the nuclei of newly generated $\mathrm{BrdU}^{+}$cells and the cells expressing the full-length TrkB receptor in the striatum $(A)$, septum $(B)$, thalamus $(C)$, and hypothalamus $(D)$. The $\mathrm{BrdU}^{+}$cells were identified with a rhodamine-conjugated secondary antibody (bright orange), and the TrkB was visualized with a fluorescein-conjugated secondary antibody ( green). The sections were visualized with either a dual fluorescein-rhodamine filter or with only a fluorescein filter (insets). In none of the four regions analyzed did the $\mathrm{BrdU}^{+}$cells (e.g., asterisks) express the TrkB receptor. Frequently, however, the $\mathrm{BrdU}^{+}$cells were adjacent to $\mathrm{TrkB}^{+}$cells. The absence of double-labeled cells suggests that the BDNF may have an indirect effect on the proliferation and/or survival of newly generated cells. Scale bar: $A-D, 30 \mu \mathrm{m}$. age of the nestin ${ }^{+}$cells in the SVZ incorporated BrdU. The low percentage of nestin ${ }^{+}-\mathrm{BrdU}^{+}$cells, in conjunction with the relatively high percentage of $\mathrm{BrdU}^{+}$cells expressing neuronal or astrocytic markers, suggests that the majority of the newly generated cells undergo differentiation.

\section{Infusion of BDNF and PBS results in the formation of "polyp-like" hyperplasias of the ventricular wall}

To determine whether the inf usion of BDNF or PBS induces the formation of "polyps" similar to those described after intracerebroventricular infusion of EGF (Kuhn et al., 1997), we analyzed the BDNF- and PBS-infused brains for the incidence of polyp formation and their phenotypic composition. Intraventricular polyps were observed protruding into the inf used lateral ventricle in both the BDNF- and PBS-infused brains. These polyps were not present in the uninfused lateral or third ventricles. After BDNF infusion, several small $(<200 \mu \mathrm{m}$ in diameter) polyps were found emanating from the wall of the lateral ventricle lining the striatum (Fig. 10B), septum, and corpus callosum. These hyperplasias consisted of cells that were predominantly $\mathrm{TuJ} 1^{+}$; very few of the cells were $\mathrm{GFAP}^{+}$(data not shown). A low proportion of the cells within the polyp were $\mathrm{BrdU}^{+}$, but the underlying ventricular wall usually contained a high proportion of $\mathrm{BrdU}^{+}$cells. In contrast, the PBS-infused brains contained considerably larger polyps (up to $600 \mu \mathrm{m}$ in diameter) that were devoid of astrocytic and neuronal markers, except for a central core containing predominantly neurons (Fig. 10A) and a low number of glia (data not shown). The polyps formed after PBSinfusion consist of a much higher density of $\mathrm{BrdU}^{+}$undifferentiated cells. The characteristics of the polyps observed after BDNF-infusion suggest that the BDNF promotes the differentiation, but perhaps not the formation, of these polyps.

\section{DISCUSSION}

Our study disputes the belief that the SVZ and hippocampus are the only areas of the forebrain that generate new neurons throughout life. In this study, we demonstrate that, $16 \mathrm{~d}$ after a $12 \mathrm{~d}$ interval of BDNF-BrdU administration, new neurons occur not only in the SVZ lining the lateral ventricle but also in the striatum, septum, thalamus, and hypothalamus. After BDNF infusion, numerous BrdU-labeled neurons were identified in restricted regions bordering the rostrocaudal extent of the lateral and third ventricles. The BrdU-immunoreactive cells were only present in regions expressing TrkB, the high-affinity receptor for BDNF. However, the TrkB ${ }^{+}$cells were not themselves BrdU ${ }^{+}$. Our study demonstrates that the adult forebrain has a greater capacity to produce new neurons than recognized previously and that exogenous BDNF can trigger an immense proliferation and appearance of new neurons in the parenchyma of the forebrain.

\section{BDNF leads to the production of newly generated cells in the adult forebrain}

Previous experiments have suggested that BDNF can promote the survival and/or differentiation of cells in vitro and in vivo. In the adult forebrain, BDNF can rescue newly formed cells that would otherwise undergo cell death (Morshead and van der Kooy, 1992). Moreover, in vitro studies have demonstrated that BDNF can promote the survival of SVZ cells in both young and senescent rats (Kirschenbaum and Goldman, 1995; Goldman et al., 1997). However, in our study, simply the prevention of cell death seems insufficient to account for the immense number of BrdU-immunoreactive cells in the SVZ, striatum, and septum, as 


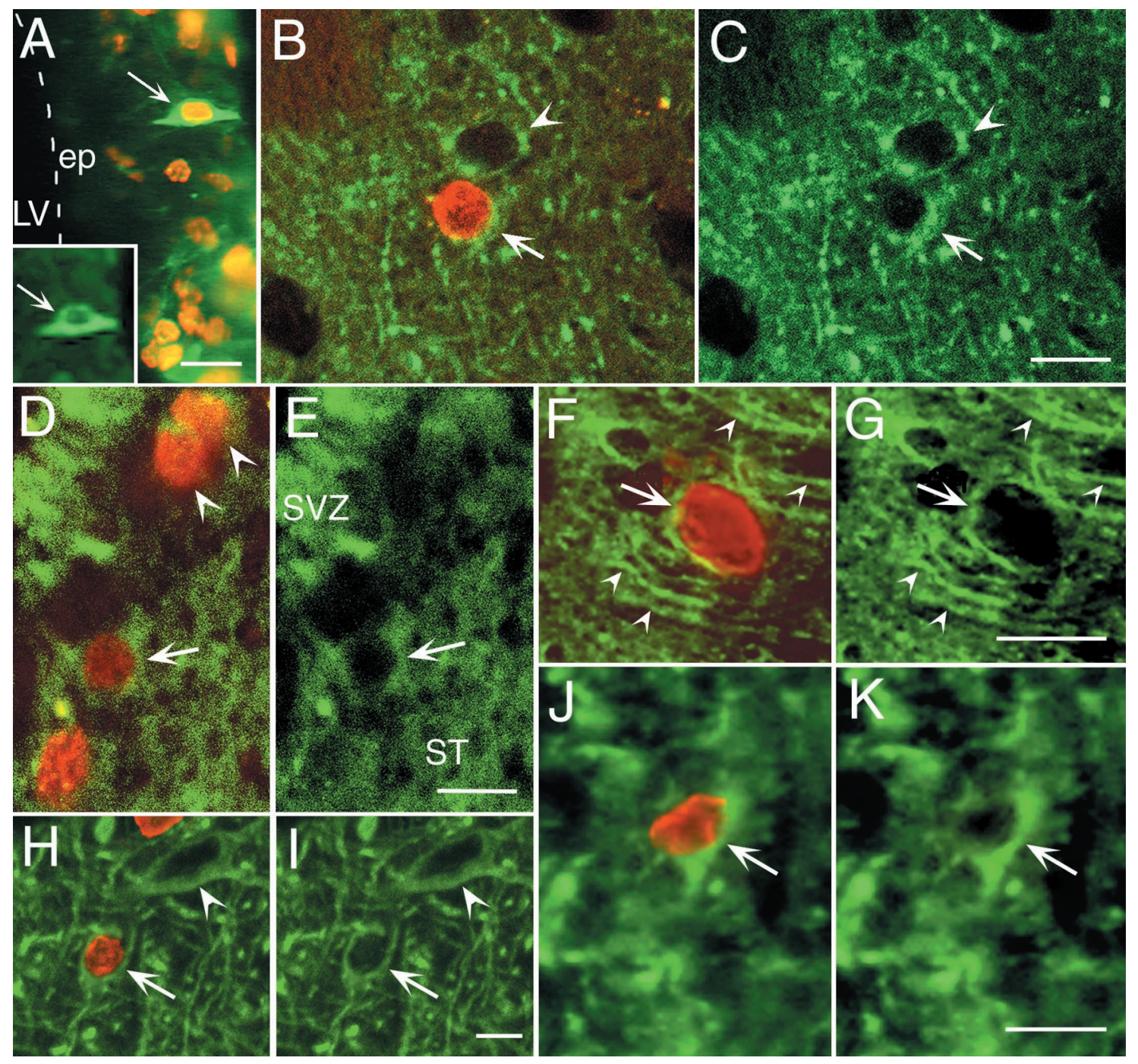

Figure 8. After the coinfusion of BDNF and BrdU into the lateral ventricle of the adult rat brain, newly generated cells in the SVZ and within the parenchyma express a neuronal phenotype. $A-K$, To analyze the phenotype of the newly generated cells, $20 \mu \mathrm{m}$ coronal sections were immunostained with anti-BrdU $(r e d)$ and the neuronal antibody TuJ1 (green) $(A-G)$ or anti-MAP-2 ( green $)(H-K)$ and then visualized with either conventional $(A, F$, $G, J, K)$ or confocal $(B-E, H, I)$ microscopy. $A$, A representative photomicrograph viewed with a dual fluorescein-rhodamine filter, demonstrating the presence of numerous $\mathrm{BrdU}^{+}$cells in the $\mathrm{SVZ}$ and the absence of $\mathrm{BrdU}^{+}$cells in the ependyma lining the lateral ventricle. The arrow designates a double-labeled $\mathrm{BrdU}^{+} / \mathrm{TuJ} 1^{+}$cell with the typical bipolar morphology of a migrating neuron. $B-E$, Representative photomicrographs of the striatal parenchyma visualized by confocal microscopy and viewed with either a dual fluorescein-rhodamine filter $(B, D)$ or with only a fluorescein filter $(C, E)$ In $B$ and $C$, the two large cells, with morphology typical of striatal neurons (e.g., arrowheads), display prominent cytoplasmic TuJ1 staining surrounding their nucleus. The lower cell (arrows) is double-labeled $\left(\mathrm{BrdU}^{+} / \mathrm{TuJ} 1^{+}\right)$. Several cells in the striatal parenchyma adjacent to the subventricular zone, shown in $D$ and $E$, are $\mathrm{BrdU}^{+}$. The neuronal phenotype of one of these cells (arrows) is established by the TuJ1 ${ }^{+}$cytoplasm $(E)$ surrounding its nucleus. The upper $\mathrm{BrdU}^{+}$cells (arrowheads) also colocalize TuJ1, but because of the plane of focus, the TuJ1 staining is not limited to the periphery of the nuclei, and therefore their neuronal phenotype cannot be definitively established. $F, G$, Representative photomicrographs of the septal parenchyma viewed with a dual fluorescein-rhodamine filter $(F)$ or with a fluorescein filter $(G)$. The $\mathrm{BrdU}^{+} / \mathrm{TuJ} 1^{+}$newly generated neuron (arrows) is flanked by numerous $\mathrm{TuJ}^{+}$fibers (e.g., arrowheads). $H-K$, Representative photomicrographs of the hypothalamic parenchyma visualized by confocal $(H, I)$ or conventional $(J, K)$ microscopy and viewed with either a dual fluorescein-rhodamine filter $(H, J)$ or with only a fluorescein filter $(I, K)$. In $H$ and $I$, two cells with a neuronal morphology display prominent MAP-2 staining of their somata and proximal processes (e.g., arrowheads). The lower cell (arrows) is a double-labeled $\left(\mathrm{BrdU}^{+} / \mathrm{MAP}^{+} 2^{+}\right)$neuron. In $J$ and $K$, one of the MAP- $2^{+}$hypothalamic neurons is also BrdU ${ }^{+} . e p$, Ependyma; $L V$, lateral ventricle; $S T$, striatum; SVZ, subventricular zone. Scale bars: $A, 25 \mu \mathrm{m} ; B, C, 10 \mu \mathrm{m} ; D, E, 10 \mu \mathrm{m} ; F, G, 10 \mu \mathrm{m} ; H, I, 10 \mu \mathrm{m} ; J, K, 10 \mu \mathrm{m}$.

well as in regions in which cell proliferation has never been described previously, such as the thalamus and hypothalamus.

Our data suggests that the BDNF inf usion triggers cell proliferation in the adult forebrain. The BDNF effects, however, must be distinguished from those of the implantation of a cannula and the infusion of the vehicle (PBS) used for BDNF delivery. Weinstein et al. (1996) showed that the insertion of a cannula into the lateral ventricle increases the proliferation of SVZ cells, suggesting that a low rate of proliferation might be induced by the mechanical disruption of the SVZ. Whether SVZ "trauma" releases neurotrophins or cytokines that cause a proliferative response remains to be determined. However, the level of proliferation after PBS-BrdU infusion is much lower than that after BDNF-BrdU administration. This discrepancy indicates that the BDNF actions are above and beyond those attained by PBS alone. Therefore, we conclude that BDNF profoundly increases the cell proliferation and/or survival of progenitor cells and their progeny. 
Table 1. Percentage of neurons and astrocytes in the SVZ and parenchyma

\begin{tabular}{|c|c|c|c|c|c|c|c|c|}
\hline \multirow[b]{2}{*}{ Infusate } & \multicolumn{2}{|c|}{ Subventricular zone } & \multicolumn{2}{|l|}{ Striatum } & \multicolumn{2}{|l|}{ Septum } & \multicolumn{2}{|l|}{ Hypothalamus } \\
\hline & $\%$ Neurons & $\%$ Astrocytes & $\%$ Neurons & $\%$ Astrocytes & $\%$ Neurons & $\%$ Astrocytes & $\%$ Neurons & $\%$ Astrocytes \\
\hline BDNF & $26.64 \pm 11.22$ & $16.85 \pm 3.36$ & $29.81 \pm 7.42$ & $6.69 \pm 3.22^{*}$ & $33.62 \pm 13.77$ & $3.11 \pm 0.31^{* *}$ & $41.66 \pm 2.63^{* *}$ & $3.31 \pm 1.26$ \\
\hline PBS & $21.82 \pm 12.49$ & $18.64 \pm 9.59$ & $23.14 \pm 10.21$ & $3.06 \pm 1.67$ & $27.03 \pm 7.65$ & $1.78 \pm 0.74$ & $21.38 \pm 12.83$ & $3.19 \pm 1.67$ \\
\hline
\end{tabular}

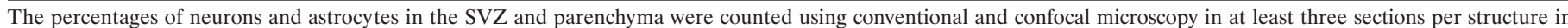

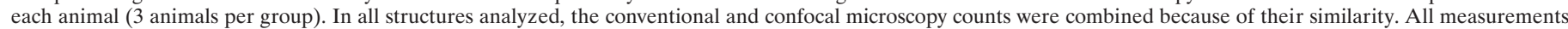
are mean \pm SEM. Statistical analyses were performed using one-way and two-way ANOVA. ${ }^{*} p<0.05 ;{ }^{*} p<0.005$.
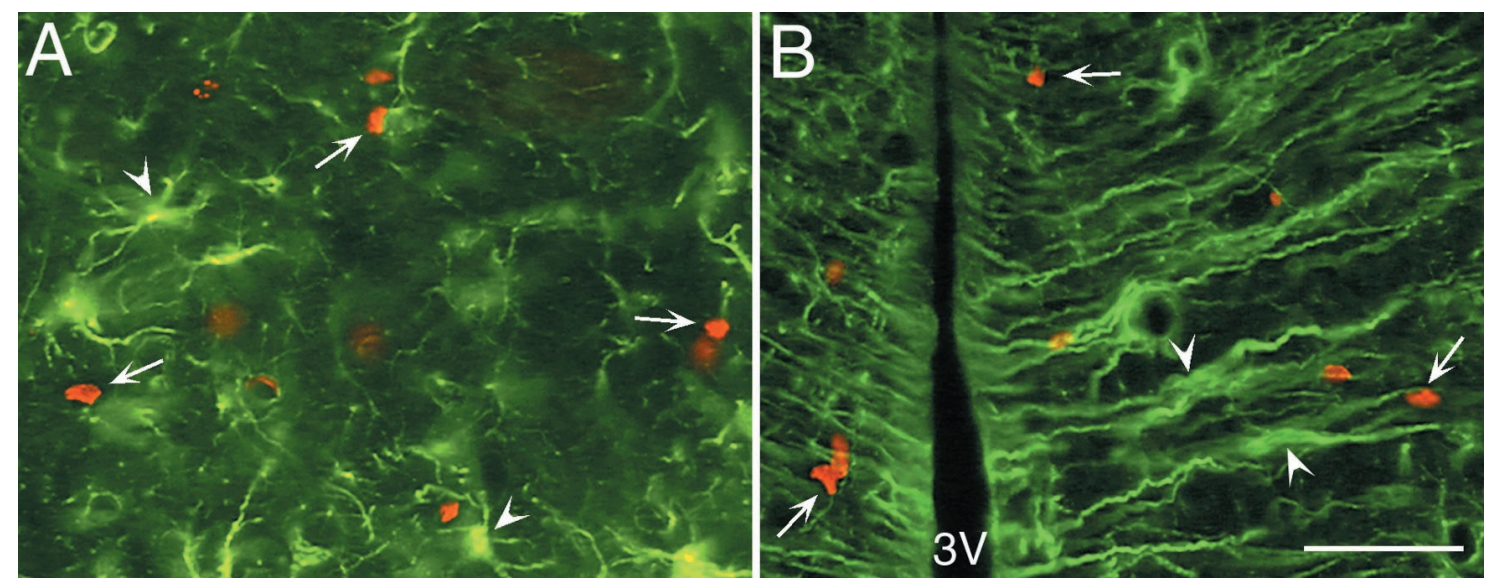

Figure 9. After coinfusion of BDNF and BrdU, most of the newly generated cells in the parenchyma of the adult rat forebrain do not express GFAP. $A, B$, Coronal sections $(20 \mu \mathrm{m})$ were immunostained with anti-BrdU (bright orange) and anti-GFAP (green) and visualized with a dual fluoresceinrhodamine filter. $A$, A representative fluorescent photomicrograph of the striatal parenchyma showing that the GFAP ${ }^{+}$cells (e.g., arrowheads) and the $\mathrm{BrdU}^{+}$nuclei (e.g., arrows) do not overlap. The absence of double-labeled $\mathrm{BrdU}^{+} / \mathrm{GFAP}^{+}$cells indicates that the newly generated cells are not astrocytes. $B$, Representative photomicrograph of the hypothalamus adjacent to the third ventricle demonstrating that, although the GFAP ${ }^{+}$cells (e.g., arrowheads) with the appearance of radial glia are intermingled with $\mathrm{BrdU}^{+}$cells, the newly generated cells are not astrocytes. $3 \mathrm{~V}$, Third ventricle. Scale bar: $A, B, 50 \mu \mathrm{m}$.

\section{Presumptive subventricular and nonsubventricular origins of the newly generated cells in the adult forebrain}

In our study, numerous newly generated cells were found in several parenchymal structures after BDNF infusion. One hypothesis to account for this distribution is that the SVZ cells divide and their progeny migrate into the nearby parenchyma, much like after the intracerebroventricular infusion of EGF (Craig et al., 1996). This scenario is also similar to the generation of new neurons in the adult primate brain reported by Gould et al. (1999). However, in our study, in contrast to that of Craig et al. (1996), we did not observe an expansion of the SVZ, with the exception of the anterior part of the SVZ and the RMS leading to the olfactory bulb. Moreover, in restricted regions such as the hypothalamus, we observed a significant number of new $\mathrm{BrdU}^{+}$ cells in the apparent absence of a SVZ. This suggests that, in agreement with Magavi et al. (2000), the SVZ may not be the only source of new neurons in the adult forebrain. Furthermore, the occurrence of newly generated cells in the parenchyma may indicate that progenitor cells are normally present in situ and are induced to divide after BDNF exposure. In fact, multipotent progenitor cells have been shown to reside in parenchymal structures of the adult forebrain (Reynolds et al., 1992; Palmer et al., 1995; Marmur et al., 1998; Laywell et al., 2000). These progenitor cells exhibit a robust proliferation in response to the in vitro exposure to particular growth factors. Furthermore, Magavi et al. (2000) demonstrated that newly generated neurons can be observed in the adult mouse cerebral cortex after lesion of layer VI neurons. The authors concluded that at least some neurons were generated in situ. In our study, a high percentage of the newly generated parenchymal cells occurred in pairs. This could arise by a number of mechanisms, including the division of "activated" cells residing in the parenchyma or, alternatively, the division within the parenchyma of progenitor cells that originated in the SVZ. Additional experiments are needed to distinguish between these possibilities. The sparse ongoing proliferation present in the adult mammalian brain may therefore be attributable to a limitation in the availability of certain growth factors and regulatory signals rather than an absence of progenitor cells.

Although the division of parenchymal progenitor cells in situ could explain the occurrence of newly generated cells in the parenchymal structures lacking a distinguishable SVZ, it is not clear whether BDNF can diffuse more than a few hundred micrometers away from the ventricular wall to directly affect distant progenitors. Previous studies have shown a negligible parenchymal diffusion of BDNF after its administration into the lumen of the lateral ventricle for $14 \mathrm{~d}$ (Yan et al., 1994; Anderson et al., 1995). Because TrkB is abundantly expressed in the SVZ surrounding the lateral ventricle (Yan et al., 1994; Zigova et al., 1998), the BDNF binding to TrkB receptors might limit the diffusion of BDNF. Therefore, the actions of BDNF could be restricted to progenitor cells situated in proximity to the ventricle, and the migration of progenitor cells into the depth of the parenchyma might be at least partially responsible for the extensive distribution of the newly generated cells. 

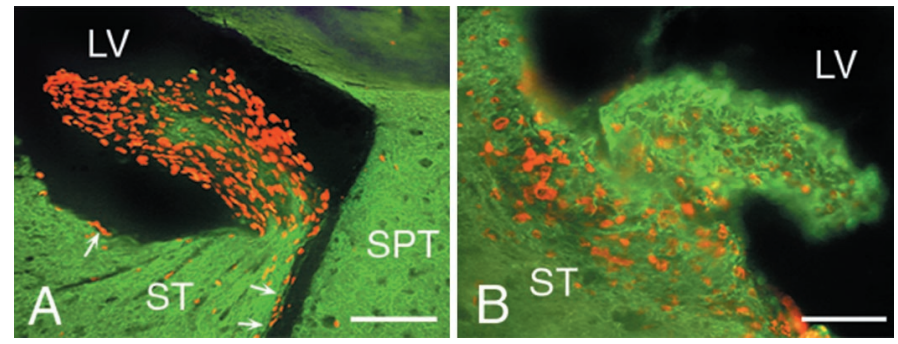

Figure 10. The protrusion of hyperplastic polyps into the lateral ventricle of the brain of an adult rat after the intracerebroventricular administration of BDNF-BrdU or PBS-BrdU. A, B, Coronal sections $(20 \mu \mathrm{m})$ stained with anti-BrdU (bright orange) and TuJ1 (green) and visualized by a dual fluorescein-rhodamine filter. $A$, A representative hyperplastic polyp situated along the striatal wall formed $16 \mathrm{~d}$ after a $12 \mathrm{~d}$ interval of intracerebroventricular PBS-BrdU administration. The polyp consists of multiple layers of $\mathrm{BrdU}^{+} / \mathrm{TuJ} 1^{-}$cells surrounding a central $\mathrm{TuJ} 1^{+} /$ $\mathrm{BrdU}^{-}$core. Notice the abundance of $\mathrm{BrdU}^{+}$cells in the polyp compared with the low number of $\mathrm{BrdU}^{+}$cells in the adjacent striatal SVZ (e.g., arrows). $B$, A representative hyperplastic polyp from the striatal wall after intracerebroventricular administration of BDNF and BrdU. The polyp contains cells with a high level of TuJ1 immunoreactivity and a low level of BrdU incorporation and is considerably smaller than the polyp in $A$ resulting from the PBS infusion, indicating that the hyperplastic polyp formed after BDNF administration is more differentiated than that after PBS infusion. Also note that, in $B$, there are numerous $\mathrm{BrdU}^{+}$cells in the striatal SVZ immediately underlying the polyp. $L V$, Lateral ventricle; $S P T$, septum; $S T$, striatum. Scale bars: $A, 100 \mu \mathrm{m} ; B, 50 \mu \mathrm{m}$.

\section{The possible direct and indirect involvement of TrkB receptors in the production of newly generated neurons in the adult forebrain}

An unexpected finding of this study was the variable level of BrdU incorporation in structures presumably exposed to a uniform concentration of BDNF-BrdU. For example, although there were numerous $\mathrm{BrdU}^{+}$cells in the thalamic habenular nuclei, there were no $\mathrm{BrdU}^{+}$cells in the overlying part of the dentate gyrus, also adjacent to the third ventricle. Moreover, the structures closest to the ventricle did not always exhibit the highest level of BrdU incorporation. For example, in the hypothalamus, there is a higher density of $\mathrm{BrdU}^{+}$cells in the paraventricular nucleus, despite its location farther away from the ventricle. An explanation for the difference in the density of $\mathrm{BrdU}^{+}$cells is that the regions with high cell proliferation have high TrkB expression, whereas the regions with a very low level of cell proliferation have low TrkB expression. Together, these findings suggest that the distribution of newly generated cells after BDNF infusion may be at least partially influenced by the pattern of BDNF expression.

Although the regions with increased cell proliferation coincide with areas of high TrkB expression, the newly generated $\mathrm{BrdU}^{+}$ cells were not $\mathrm{TrkB}^{+}$. The absence of the TrkB receptor from the membrane of the $\mathrm{BrdU}^{+}$cells may indicate that BDNF does not act directly on progenitor cells but rather initially influences the cells surrounding them. This notion is supported by our confocal analysis in which $\mathrm{TrkB}^{+}$cells were frequently adjacent to $\mathrm{BrdU}^{+}$ cells. The possibility that $\operatorname{TrkB}^{+}$cells exert a paracrine influence on progenitors cannot be ruled out. Another hypothesis to account for the absence of TrkB receptor from the membrane of the newly generated cells is the downregulation of the TrkB receptor after BDNF exposure. Alternatively, after binding BDNF, the progenitor cells may internalize their TrkB receptor, which results in the masking of the antigenic sites recognized by our antibody. Previous studies have shown that internalization and transport of the ligand-receptor complex are required to initiate some responses to neurotrophins (Bergeron et al., 1995; Z hang et al., 2000). Hence, it will be important to elucidate whether the internalization of the BDNF-TrkB complex plays a role in the survival and/or differentiation of the newly generated cells after $\mathrm{BDNF}$ infusion of the adult forebrain.

\section{Concluding remarks on the potential relevance of BDNF infusion to strategies for neuronal replacement}

Recent studies have demonstrated that, in brains affected by neurodegenerative diseases, discrete regions characterized by loss of neurons have abnormally low levels of BDNF expression. In particular, Ferrer et al. (2000) have shown that, in Huntington's disease, BDNF is reduced by $53-82 \%$ in the caudate and putamen, two regions exhibiting neuronal loss. Similar studies also suggest that, in Alzheimer's disease, decreased levels of BDNF leads to lack of trophic support for susceptible neurons, and thus, contributes to the degeneration of specific neuronal populations (Hock et al., 2000). Collectively, these findings indicate that BDNF is important for the survival of certain neuronal populations in the adult forebrain. Thus, if BDNF could be provided exogenously, it could potentially serve to promote the formation of numerous new neurons in extensive regions of the mammalian brain. Our future studies will seek to reveal whether BDNF can rescue degenerated neurons or help achieve replacement of neurons already lost as a result of a disease process.

\section{REFERENCES}

Altman J, Das GD (1965) Autoradiographic and histological evidence of postnatal hippocampal neurogenesis in rats. J Comp Neurol 124:319-335.

Alvarez-Buylla A, Theelen M, Nottebohm F (1990) Proliferation "hot spots" in adult avian ventricular zone reveals radial cell division. Neuron 5:101-109.

Anderson KD, Alderson RF, Altar CA, DiStefano PS, Corcoran TL, Lindsay RM, Wiegand SJ (1995) Differential distribution of exogenous BDNF, NGF, and NT-3 in the brain corresponds to the relative abundance and distribution of high-affinity and low-affinity neurotrophin receptors. J Comp Neurol 357:296-317.

Bergeron JJ, Di Guglielmo GM, Baass PC, Authier F, Posner BI (1995) Endosomes, receptor tyrosine kinase internalization and signal transduction. Biosci Rep 15:411-418.

Bernhardt R, Huber G, Matus A (1985) Differences in the developmental patterns of three microtubule associated proteins in the rat cerebellum. J Neurosci 5:977-991.

Bignami A, Eng LF, Dahl D, Uyeda CT (1972) Localization of the glial fibrillary acidic protein in astrocytes by immunofluorescence. Brain Res 43:429-435.

Cheng CM, Joncas G, Reinhardt RR, Farrer R, Quarles R, Janssen J, McDonald MP, Crawley JN, Powell-Braxton L, Bondy CA (1998) Biochemical and morphometric analyses show that myelination in the insulin-like growth factor 1 null brain is proportionate to its neuronal composition. J Neurosci 18:5673-5681.

Chiasson BJ, Tropepe V, Morshead CM, van der Kooy D (1999) Adult mammalian forebrain ependymal and subependymal cells demonstrate proliferative potential, but only subependymal cells have neural stem cell characteristics. J Neurosci 19:4462-4471.

Craig CG, Tropepe V, Morshead CM, Reynolds BA, Weiss S, van der Kooy D (1996) In vivo growth factor expansion of endogenous subependymal neural precursor cell populations in the adult mouse brain. J Neurosci 16:2649-2658.

Easter Jr SS, Ross LS, Frankfurter A (1993) Initial tract formation in the mouse brain. J Neurosci 13:285-299.

Ferrer I, Goutan E, Marin C, Rey MJ, Ribalta T (2000) Brain-derived neurotrophic factor in Huntington disease. Brain Res 866:257-261.

Frederiksen K, McKay RD (1988) Proliferation and differentiation of rat neuroepithelial precursor cells in vivo. J Neurosci 8:1144-1151.

Goldman SA, Kirschenbaum B, Harrison-Restelli C, Thaler HT (1997) Neuronal precursors of the adult rat subependymal zone persist into senescence, with no decline in spatial extent or response to BDNF. J Neurobiol 32:554-566.

Gould E, Reeves AJ, Graziano MS, Gross CG (1999) Neurogenesis in the neocortex of adult primates. Science 286:548-552.

Graziadei PPC, Monti Graziadei GA (1976) Neurogenesis and neuron regeneration in the olfactory system of mammals. III. Deafferentation 
and reinnervation of the olfactory bulb following section of the fila olfactoria in rat. J Neurocytol 9:145-162.

Gritti A, Frolichsthal-Schoeller P, Galli R, Parati EA, Cova L, Pagano SF, Bjornson CR, Vescovi AL (1999) Epidermal and fibroblast growth factors behave as mitogenic regulators for a single multipotent stem cell-like population from the subventricular region of the adult mouse forebrain. J Neurosci 19:3287-3297.

Hock C, Heese K, Hulette C, Rosenberg C, Otten U (2000) Regionspecific neurotrophin imbalances in Alzheimer disease: decreased levels of brain-derived neurotrophic factor and increased levels of nerve growth factor in hippocampus and cortical areas. Arch Neurol 57:846-851.

Hockfield S, McKay RD (1985) Identification of major cell classes in the developing mammalian nervous system. J Neurosci 5:3310-3328.

Huard JM, Youngentob SL, Goldstein BJ, Luskin MB, Schwob JE (1998) Adult olfactory epithelium contains multipotent progenitors that give rise to neurons and non-neural cells. J Comp Neurol 400:469-486.

Johnson GV, Jope RS (1992) The role of microtubule-associated protein 2 (MAP-2) in neuronal growth, plasticity, and degeneration. J Neurosci Res 33:505-512.

Kaplan MS, Bell DH (1984) Mitotic neuroblasts in the 9-day-old and 11-month-old rodent hippocampus. J Neurosci 4:1429-1441.

Kirschenbaum B, Goldman SA (1995) Brain-derived neurotrophic factor promotes the survival of neurons arising from the adult rat forebrain subependymal zone. Proc Natl Acad Sci USA 92:210-214.

Kuhn HG, Dickinson-Anson H, Gage FH (1996) Neurogenesis in the dentate gyrus of the adult rat: age-related decrease of neuronal progenitor proliferation. J Neurosci 16:2027-2033.

Kuhn HG, Winkler J, Kempermann G, Thal LJ, Gage FH (1997) Epidermal growth factor and fibroblast growth factor-2 have different effects on neural progenitors in the adult rat brain. $\mathrm{J}$ Neurosci 17:5820-5829.

Laywell ED, Rakic P, Kukekov VG, Holland EC, Steindler DA (2000) Identification of a multipotent astrocytic stem cell in the immature and adult mouse brain. Proc Natl Acad Sci USA 97:13883-13888.

Lee MK, Rebhun LI, Frankfurter A (1990) Posttranslational modification of class III beta-tubulin. Proc Natl Acad Sci USA 87:7195-7199.

Lendahl U, McKay RD (1990) The use of cell lines in neurobiology. Trends Neurosci 13:132-137.

Levison SW, Goldman JE (1993) Both oligodendrocytes and astrocytes develop from progenitors in the subventricular zone of postnatal rat forebrain. Neuron 10:201-212.

Lois C, Alvarez-Buylla A (1994) Long-distance neuronal migration in the adult mammalian brain. Science 264:1145-1148.

Luskin MB (1993) Restricted proliferation and migration of postnatally generated neurons derived from the forebrain subventricular zone. Neuron 11:173-189.

Magavi SS, Leavitt BR, Macklis JD (2000) Induction of neurogenesis in the neocortex of adult mice. Nature 405:951-955.

Marmur R, Mabie PC, Gokhan S, Song Q, Kessler JA, Mehler MF (1998) Isolation and developmental characterization of cerebral cortical multipotent progenitors. Dev Biol 204:577-591.

Morshead CM, van der Kooy D (1992) Postmitotic death is the fate of constitutively proliferating cells in the subependymal layer of the adult mouse brain. J Neurosci 12:249-256.

Morshead CM, Reynolds BA, Craig CG, McBurney MW, Staines WA, Morassutti D, Weiss S, van der Kooy D (1994) Neural stem cells in the adult mammalian forebrain: a relatively quiescent subpopulation of subependymal cells. Neuron 13:1071-1082.

Palmer TD, Ray J, Gage FH (1995) FGF-2-responsive neuronal progenitors reside in proliferative and quiescent regions of the adult rodent brain. Mol Cell Neurosci 6:474-486.

Palmer TD, Takahashi J, Gage FH (1997) The adult rat hippocampus contains primordial neural stem cells. Mol Cell Neurosci 8:389-404.

Paxinos G, Watson C (1982) The rat brain in stereotaxic coordinates. New York: Academic.

Pencea V, Bingaman KB, Wiegand SJ, Luskin MB (1999) Infusion of $\mathrm{BDNF}$ into the lateral ventricle of the adult rat leads to an increase in the number of newly generated cells in the fore, mid and hindbrain parenchyma. Soc Neurosci Abstr 25:2045.

Privat A (1975) Postnatal gliogenesis in the mammalian brain. Int Rev Cytol 40:281-323.

Raedler E, Raedler A (1978) Autoradiographic study of early neurogenesis in rat neocortex. Anat Embryol (Berl) 154:267-284.

Ranscht B, Clapshaw PA, Price J, Noble M, Seifert W (1982) Development of oligodendrocytes and Schwann cells studied with a monoclonal antibody against galactocerebroside. Proc Natl Acad Sci USA 79:2709-2713.

Ranscht B, Wood PM, Bunge RP (1987) Inhibition of in vitro peripheral myelin formation by monoclonal anti-galactocerebroside. J Neurosci 7:2936-2947.

Reynolds BA, Weiss S (1992) Generation of neurons and astrocytes from isolated cells of the adult mammalian central nervous system. Science 255:1707-1710.

Reynolds BA, Weiss S (1996) Clonal and population analyses demonstrate that an EGF-responsive mammalian embryonic CNS precursor is a stem cell. Dev Biol 175:1-13.

Reynolds BA, Tetzlaff W, Weiss S (1992) A multipotent EGFresponsive striatal embryonic progenitor cell produces neurons and astrocytes. J Neurosci 12:4565-4574.

Schlessinger AR, Cowan WM, Gottlieb DI (1975) An autoradiographic study of the time of origin and the pattern of granule cell migration in the dentate gyrus of the rat. J Comp Neurol 159:149-175.

Sidman RL, Rakic P (1973) Neuronal migration, with special reference to developing human brain: a review. Brain Res 62:1-35.

Vaysse PJ, Goldman JE (1990) A clonal analysis of glial lineages in neonatal forebrain development in vitro. Neuron 5:227-235.

Weinstein DE, Burrola P, Kilpatrick TJ (1996) Increased proliferation of precursor cells in the adult rat brain after targeted lesioning. Brain Res 743:11-16.

Yan Q, Matheson C, Sun J, Radeke MJ, Feinstein SC, Miller JA (1994) Distribution of intracerebral ventricularly administered neurotrophins in rat brain and its correlation with trk receptor expression. Exp Neurol 127:23-36.

Zhang Y, Moheban DB, Conway BR, Bhattacharyya A, Segal RA (2000) Cell surface Trk receptors mediate NGF-induced survival while internalized receptors regulate NGF-induced differentiation. J Neurosci 20:5671-5678.

Zigova T, Betarbet R, Soteres BJ, Brock S, Bakay RA, Luskin MB (1996) A comparison of the patterns of migration and the destinations of homotopically transplanted neonatal subventricular zone cells and heterotopically transplanted telencephalic ventricular zone cells. Dev Biol 173:459-474.

Zigova T, Pencea V, Wiegand SJ, Luskin MB (1998) Intraventricular administration of BDNF increases the number of newly generated neurons in the adult olfactory bulb. Mol Cell Neurosci 11:234-245. 